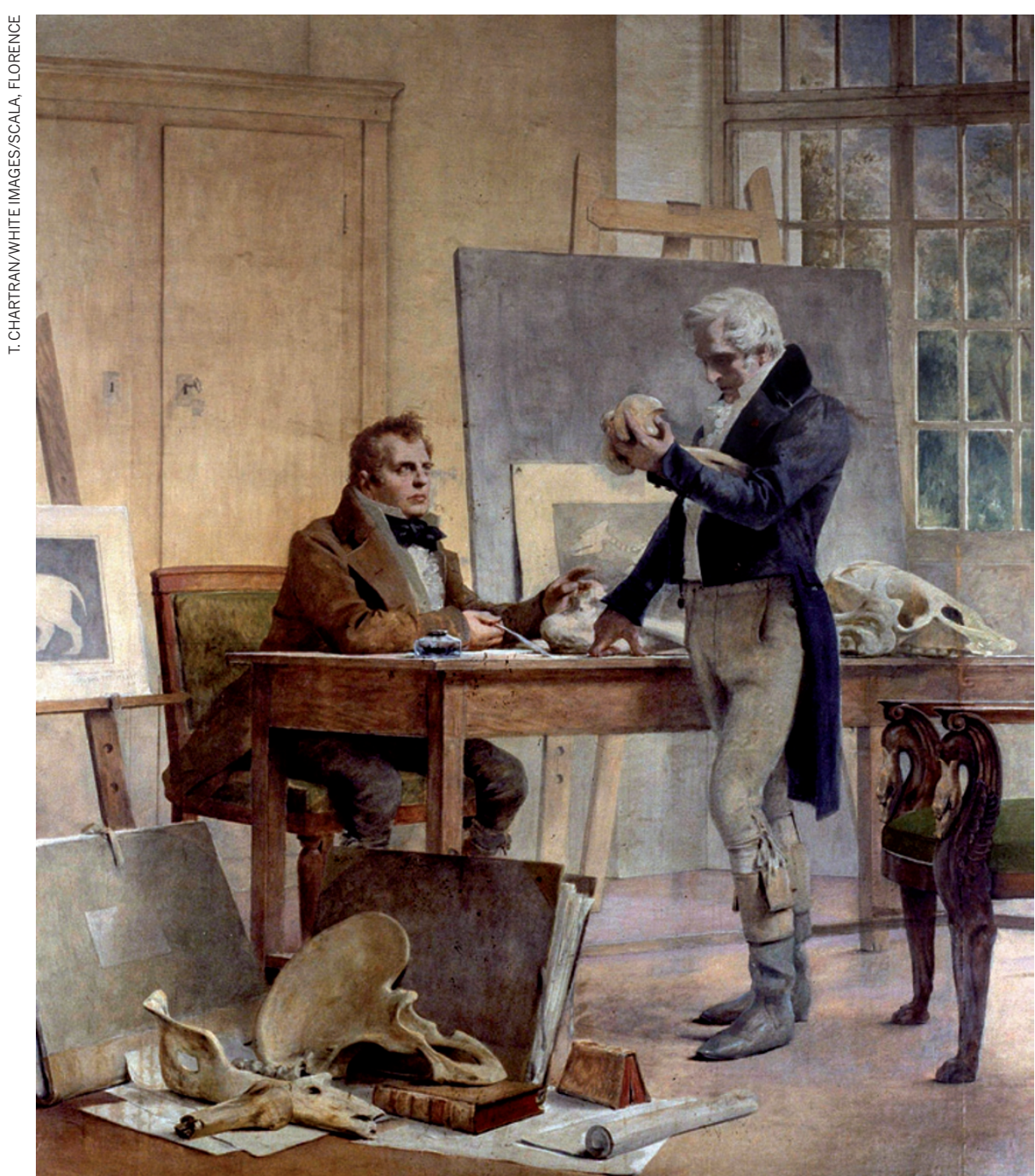

Georges Cuvier (standing) was one of dozens of naturalists who laid the groundwork for Charles Darwin.

\title{
NATURAL SELECTION
}

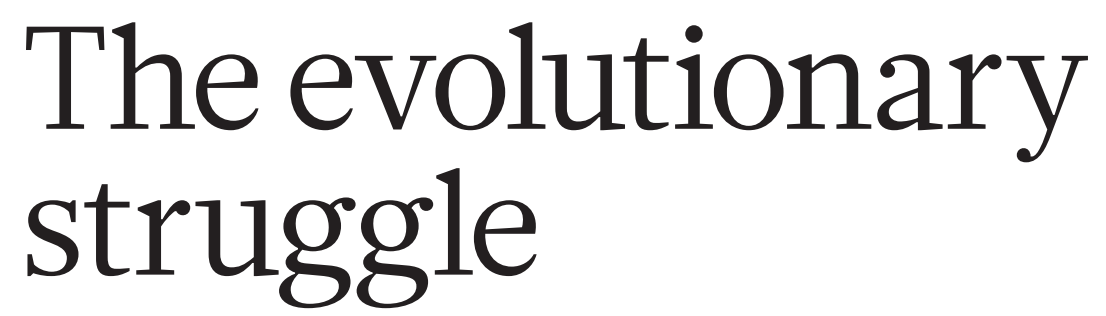

\section{Andrew Berry enjoys a biographical feast that turns the spotlight onto Darwin's forerunners.}

\section{I} $\mathrm{t}$ is remarkable that the theory of evolution has come to be associated exclusively with Charles Darwin. Even Alfred Russel Wallace, co-author of the paper that first unveiled evolution by natural selection, has mostly disappeared from view. In Darwin's Ghosts, novelist and science historian Rebecca Stott explores the intellectual origins of the theory of natural selection through scientific biographies of Darwin's antecedents and contemporaries, from Aristotle to Wallace.
The usual suspects are here, including French naturalists Jean-Baptiste Lamarck, Georges Cuvier and Georges-Louis Leclerc, Count of Buffon. But so are people whose contributions to the history of evolutionary theory are generally known only in history of science departments, such as Swiss biologist Abraham Trembley and French natural historian Benoît de
Maillet. Stott's research is broad and unerring; her book is wonderful.

On the Origin of Species (John Murray, 1859) was rushed out. In June 1858, Darwin got a letter from Wallace, then in Indonesia, suggesting the idea evolution by natural selection - that Darwin had been quietly gestating for 20 years. Only intervention by colleagues saved Darwin's claim to precedence. The outcomes were a paper co-published by Darwin and Wallace in the Journal of the Proceedings of the Linnean Society in July 1858, and Origin in November the next year.

After the publication, Darwin's materialistic vision of biological change was, as he had feared, condemned as heretical. But blasphemy was not the only charge laid at his door: some of Darwin's correspondents complained that he had plagiarized their work.

Darwin saw Origin as a quick and dirty synopsis of his ideas, not the planned 'big species book', as he referred to it. One casualty was a review of the literature. As Stott recounts, Darwin dealt with this oversight (and the critical letters) in 1861, by adding a review, An Historical Sketch of the Recent Progress of Opinion on the Origin of Species, to the third edition. Stott's book presents encounters with the inhabitants of this addendum, plus a few who did not make Darwin's cut.

The Sketch was an honest attempt to give credit where it was due. But it is clear that Darwin was keen, by omission, to emphasize his own claim to the theory. Wallace is mentioned just four times in the 490 pages of the first edition of Origin. And in his autobiography, Darwin downplayed the influence of his grandfather, Erasmus Darwin, whose evolutionary speculations were both historically significant and part of his family's lore.

In looking beyond Darwin, Stott deals with eye-wateringly complicated material. A three-way chapter on Lamarck, Cuvier and fellow French naturalist Étienne Geoffroy, for instance, describes - with a novelist's eye for dramatic detail - how, in the early nineteenth century, they jockeyed for preeminence at the newly formed French National Museum of Natural History in Paris.

More than the story of three careers, this is also about the waxing and waning of friendships, a clash of deeply opposed world views and some of the most exciting and innovative science ever done. And the story is complicated by difficulties in interpreting the documentary record, which is mostly a monument to courtesy. Cuvier long suppressed his unfavourable view of Lamarck, waiting instead 
- to bury both Lamarck's ideas and their author with a single brutal obituary, published in the Memoirs of the Royal Academy of Sciences of the Institute of France in 1835.

Stott highlights the charged moment when Cuvier first examined mummified ibises collected by Geoffroy on the Napoleonic expedition to Egypt. Here was the ultimate showdown between Lamarck's evolutionary ideas, which predicted that ibises should have experienced species change in the 3,000 years since the specimens were alive, and Cuvier's insistence that this was biologically impossible. Were the ancient ibis mummies significantly different from modern birds? No Cuvier seemed to have been proved right.

Many of the heroes of Darwin's Ghosts ran risks to pursue their evolutionary ideas - in 1749, for example, French philosopher Denis Diderot was imprisoned for subversive writings that touched on species variation. Many thinkers tried to sidestep the charge of heresy: de Maillet, for example, distanced himself by presenting his theories in the form of a supposed conversation with an Indian mystic, 'Telliamed' (de Maillet spelled backwards). Erasmus Darwin, anxious about the impact of controversy on his reputation as a doctor, chose to veil many of his evolutionary speculations behind a cloak of classicstinged poetry. Scottish geologist Robert Chambers never publicly admitted that he was the author of the anonymous Victorian best-seller Vestiges of the Natural History of Creation (John Churchill, 1848).

The lesson of Stott's book is that Darwin and Wallace were not just standing on the shoulders of giants scientifically. They were also at liberty to speculate and publish freely on the topic only because of the risks that these earlier writers had taken.

Stott introduces us to a sparkling cast of characters, but the biographical approach has its limitations. The book fails to illuminate the most remarkable aspect of the story of the discovery of evolution: that this long-sought-after idea was discovered independently, around the same time, by two men who both regarded themselves as pedestrian thinkers.

The Darwin-Wallace story validates the modern insistence that discovery is not about 'great men', but about a confluence of societal and technological factors that collectively make a previously inaccessible idea accessible. Nevertheless, Stott's constellation of biographies is an exhilarating romp through 2,000 years of fascinating scientific history.

Andrew Berry is a lecturer in evolutionary biology and teaches history of science at Harvard University in Cambridge, Massachusetts. e-mail:berry@oeb.harvard.edu

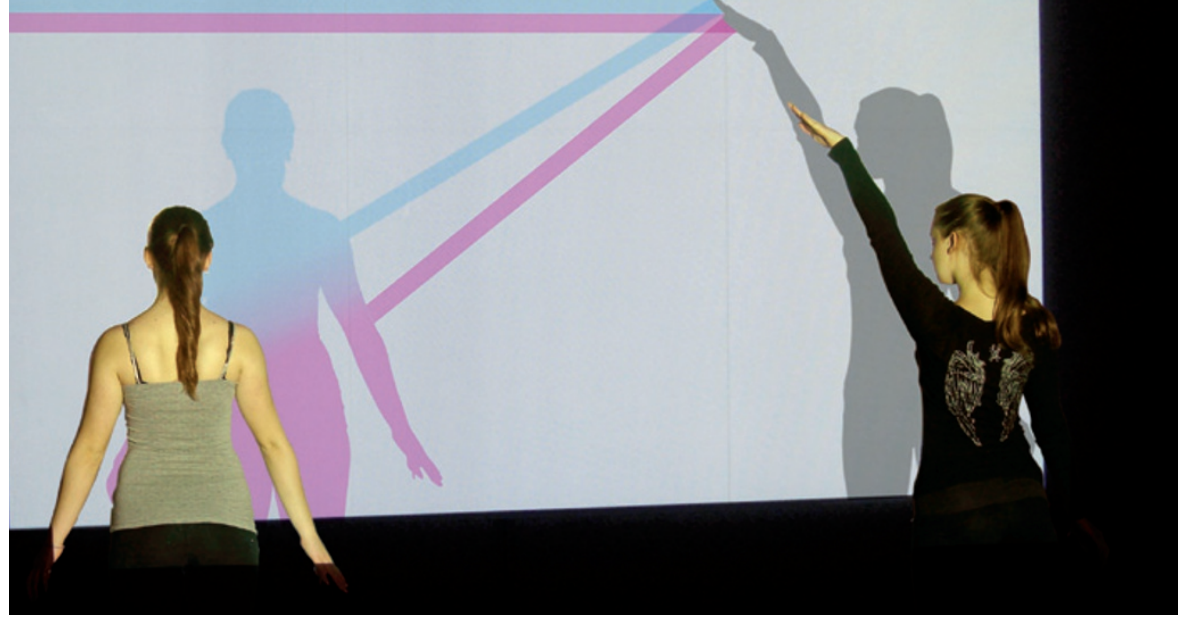

Social Light at the Science Museum in London lets audience members act as mirrors.

\section{Q\&A Scott Snibbe}

\section{Nature's digitizer}

Media designer Scott Snibbe creates software apps and interactive science-museum installations, and was executive producer of the 2011 Biophilia project by singer-songwriter Björk. As he prepares to lecture at the Sónar International Festival of Advanced Music and New Media Art in São Paulo, Brazil - where his visuals will accompany Björk's performance of Biophilia - he talks about provoking wonder.

\section{How did you become a digital designer?}

My father is an inventor who designed a geometric kite and is working on a perpetual-motion machine. My mother is an artist. From childhood I wanted to be a combination of the two. My parents let me use a machine workshop from the age of four to make anything, however useless. My dad and I built a Tesla coil, and I got a few 20,000-volt shocks, but my parents weren't afraid because we were Christian Scientists, and didn't believe that God would allow us to get hurt as long as we had a positive attitude and safety goggles. At university, I considered studying genetics or neuroscience, but I couldn't handle dissections or vivisections. Instead, I became a researcher at the computer-human interface, working on problems such as artificial touch and computer vision at places including Brown University in Providence, Rhode Island, and Adobe Systems in Seattle, Washington. Then I created my own companies, combining interactive art with business.

\section{What draws you to interactive apps?}

Other fields are limited by money, equipment and the laws of nature. But with computers, the only limits are technical ability, ingenuity and imagination. Nature has awed me since I was a child, but the educational system rarely conveys this wonder, transforming our Universe into boring multiple-choice $\checkmark$ NATURE,COM For an interview with Bjork on Biophilia, visit:

go.nature.com/18n54h

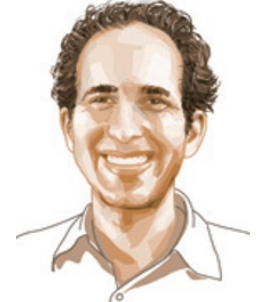

Sónar International Festival of Advanced Music and New Media Art Anhembi Parque, São Paolo, Brazil. 11-12 May 2012. questions. My programs recreate the wonder and magic to give people the kind of experiences that they have in wild places such as river banks. My apps borrow from nature, but the laws are slightly altered, as if in a parallel universe.

\section{Can you describe your} science-based apps? With my Gravilux, you touch the screen and stars are attracted to your fingertips. I started with Newton's gravity equations but didn't get controllable patterns, so I removed mutual attraction. Bubble Harp draws Voronoi diagrams, based on a geometric algorithm first described by seventeenth-century philosopher René Descartes, and used to model the structure of cells, the pattern of human settlements and the gravitational influence of stars. With Antograph, you 'paint' a pheromone that attracts ants, but they swarm off the trail, just as real ants would. I've had reports of it being used to teach what pheromones are, and one user of Gravilux said that it helped him to get an A grade in physics for the first time.

\section{How did you come to work with Björk?}

Björk chose to release Biophilia on the iPad. She asked my studio to produce the 